\title{
Classification of Dopamine Receptor Genes in Vertebrates: Nine Subtypes in Osteichthyes
}

\author{
Kei Yamamoto Romain Fontaine Catherine Pasqualini Philippe Vernier \\ Paris-Saclay Institute of Neuroscience (UMR 9197), CNRS - Université Paris-Sud, Université Paris-Saclay, \\ Gif-sur-Yvette, France
}

\author{
Key Words \\ Dopamine receptor $\cdot$ Evolution $\cdot$ Gene duplication $\cdot$ Gene \\ loss · Phylogeny · Osteichthyes · Tetrapod - Teleost . \\ Vertebrates
}

\begin{abstract}
Dopamine neurotransmission regulates various brain functions, and its regulatory roles are mediated by two families of $G$ protein-coupled receptors: the $D_{1}$ and $D_{2}$ receptor families. In mammals, the $D_{1}$ family comprises two receptor subtypes $\left(D_{1}\right.$ and $\left.D_{5}\right)$, while the $D_{2}$ family comprises three receptor subtypes $\left(D_{2}, D_{3}\right.$ and $\left.D_{4}\right)$. Phylogenetic analyses of dopamine receptor genes strongly suggest that the common ancestor of Osteichthyes (bony jawed vertebrates) possessed four subtypes in the $D_{1}$ family and five subtypes in the $D_{2}$ family. Mammals have secondarily lost almost half of the ancestral dopamine receptor genes, whereas nonmammalian species kept many of them. Although the mammalian situation is an exception among Osteichthyes, the current classification and characterization of dopamine receptors are based on mammalian features, which have led to confusion in the identification of dopamine receptor subtypes in nonmammalian species. Here we begin by reviewing the history of the discovery of dopamine receptors in vertebrates.
\end{abstract}

The recent genome sequencing of coelacanth, gar and elephant shark led to the proposal of a refined scenario of evolution of dopamine receptor genes. We also discuss a current problem of nomenclature of dopamine receptors. Following the official nomenclature of mammalian dopamine receptors from $D_{1}$ to $D_{5}$, we propose to name newly identified receptor subtypes from $D_{6}$ to $D_{9}$ in order to facilitate the use of an identical name for orthologous genes among different species. To promote a nomenclature change which allows distinguishing the two dopamine receptor families, a nomenclature consortium is needed. This comparative perspective is crucial to correctly interpret data obtained in animal studies on dopamine-related brain disorders, and more fundamentally, to understand the characteristics of dopamine neurotransmission in vertebrates.

c) 2015 S. Karger AG, Basel

\section{Introduction}

Dopamine is one of the most intensively studied modulatory neurotransmitters due to its implication in many brain functions such as neuroendocrine regulation, motor programming, motivational behaviors, learning and memory [Hornykiewicz, 1966; Vogt, 1973; Tuomisto and

\section{KARGER 125}

C 2015 S. Karger AG, Basel

$0006-8977 / 15 / 0864-0164 \$ 39.50 / 0$ 
Mannisto, 1985; Gerfen et al., 1987; Schultz, 1998; Goldman-Rakic, 1999; Matsumoto et al., 1999; Kehagia et al., 2010]. Dopamine exerts its actions on target cells by activating specific membrane receptors. In mammals, five dopamine receptor genes have been isolated, and they have been characterized extensively over the last 30 years.

Dopamine receptors are more numerous in other groups of vertebrates. Thus, several types of dopamine receptors found in nonmammalian species do not have a one-to-one homologous counterpart with mammalian dopamine receptors. The data obtained in different vertebrate species are therefore difficult to interpret and compare. In addition, the 'official' classification and nomenclature of dopamine receptors are based only on the set of receptors found in placental mammals. This hampers meaningful and coherent comparison of the effects of dopamine receptor agonists/antagonists between mammalian and nonmammalian species. To alleviate this problem, defining relations of homology among dopamine receptor genes in vertebrates is essential.

Here we review the history of the discovery of dopamine receptors in mammals and other vertebrate groups, and then summarize the classification of dopamine receptors based on evolutionary analyses. We conclude by reviewing the problem posed by the mammalian-centered nomenclature of dopamine receptors, and provide a broader view of dopamine receptor evolution in vertebrates.

\section{Two Families of Dopamine Receptors in Mammals}

Before the molecular era, two categories of dopamine receptors, named $\mathrm{D}_{1}$ and $\mathrm{D}_{2}$, were identified based on pharmacological, biochemical and physiological criteria. The $\mathrm{D}_{1}$ receptor is defined by specific agonists that increase cAMP synthesis and by antagonists that block this effect. By contrast, agonists of the $\mathrm{D}_{2}$ receptor inhibit cAMP synthesis or modulate other signaling pathways, and these effects are blocked by a series of $\mathrm{D}_{2}$ receptor antagonists, including antipsychotic drugs [Kebabian and Calne, 1979; Beaulieu and Gainetdinov, 2011].

Molecular cloning techniques led to the isolation of DNA sequences from rat and human, confirming that $D_{1}$ and $\mathrm{D}_{2}$ receptors are encoded by different genes [Bunzow et al., 1988; Dearry et al., 1990; Monsma et al., 1990; Sunahara et al., 1991]. These DNA sequences also led to the discovery that dopamine receptors are membrane proteins with seven hydrophobic segments, a structural signature of the $G$ protein-coupled receptor. $D_{1}$ and $D_{2}$ re-

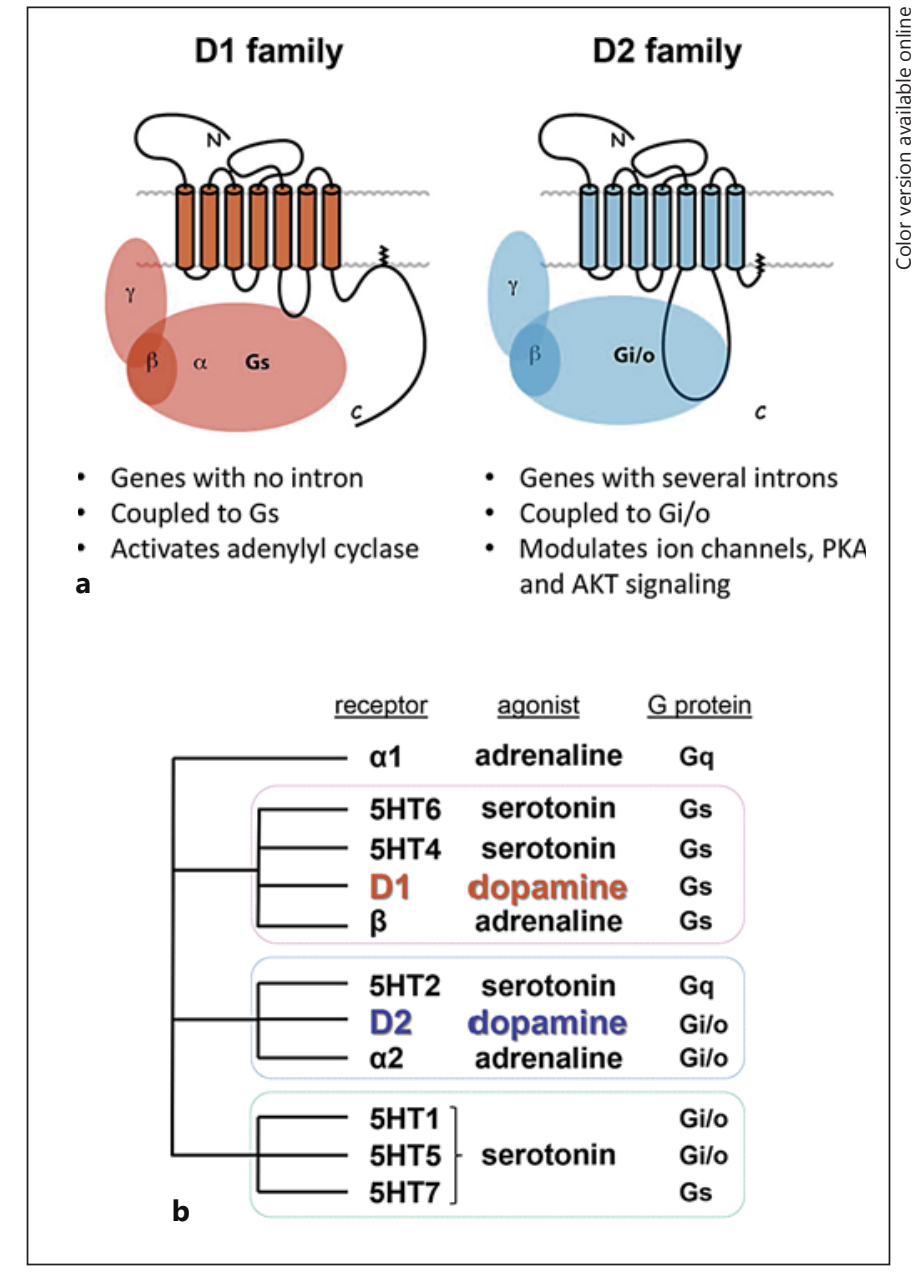

Fig. 1. Two different classes of dopamine receptors. a Schema of the structure of $D_{1}$ and $D_{2}$ families of dopamine receptors. The two families possess different characteristics in terms of genomic structure, G protein coupling and physiological effects. b A simplified phylogenetic tree showing the relationship of $D_{1}$ and $D_{2}$ families with other monoamine receptors in vertebrates [modified from Yamamoto et al., 2013]. Monoamine receptors sharing the same natural agonist are not necessarily close to each other.

ceptors both belong to group A (rhodopsin-like) of the G protein-coupled receptor superfamily, but have different structural features (fig. 1a). The $D_{1}$ receptor gene is intronless, and the deduced structure of the $\mathrm{D}_{1}$ receptor protein exhibits a short third cytoplasmic loop and a long $\mathrm{C}$-terminal tail. When this sequence is expressed in heterologous cells, the receptor is coupled to the Gs family of $G$ proteins, and $D_{1}$ receptor agonists promote adenylyl cyclase activity in those cells. In contrast to the $D_{1}$ receptor, the $D_{2}$ dopamine receptor gene contains several in- 
trons and encodes a long third cytoplasmic loop and a short C-terminal tail. In heterologous cells, the $\mathrm{D}_{2}$ receptor is coupled to the Gi/Go family of G proteins, and its agonists inhibit adenylyl cyclase activity. Although functions of the $\mathrm{D}_{1}$ and $\mathrm{D}_{2}$ receptors are often described by their effects on cAMP production, dopamine receptors also regulate a number of other signal transduction pathways, including calcium and potassium channels and arachidonic acid synthesis, thus providing versatile signal modulations to a single cell [reviewed in Jaber et al., 1996; Missale et al., 1998; Sidhu and Niznik, 2000; Vallone et al., 2000].

After the first two $D_{1}$ and $D_{2}$ receptors were isolated, other dopamine receptor-related sequences were discovered. Three of them were initially identified in rats: two different $\mathrm{D}_{1}$-like receptor genes which encode proteins that are able to activate adenylyl cyclase, termed $D_{1 A}$ and $D_{1 B}$ [Monsma et al., 1990; Tiberi et al., 1991], and a novel $\mathrm{D}_{2}$-related receptor [Sokoloff et al., 1990]. Despite its high sequence similarity to the $D_{2}$ receptor gene, its pharmacological profiles and tissue distribution were distinct from those of $\mathrm{D}_{1}$ or $\mathrm{D}_{2}$ receptors. Thus, it was identified as a 'third' subtype and accordingly named the $D_{3}$ dopamine receptor. Finally, $D_{4}$ and $D_{5}$ receptor genes were identified from human genomic DNA. Although the sequence of the $D_{4}$ receptor gene was similar to $D_{2}$ and $D_{3}$ receptor genes, it displayed higher affinity to clozapine than the other subtypes of dopamine receptors [Van Tol et al., 1991]. The $\mathrm{D}_{5}$ receptor showed the highest sequence similarity with the known $\mathrm{D}_{1}$ receptor and the biochemical properties similar to $\mathrm{D}_{1}$ stimulating adenylyl cyclase, but displayed higher affinity for dopamine than the $\mathrm{D}_{1}$ receptor [Sunahara et al., 1991].

Later studies revealed that the human $D_{5}$ and the rat $D_{1 B}$ receptor sequences are in fact orthologous [Jarvie et al., 1993]. Genes are referred to as 'orthologous' when homologous sequences present in different species originate from a gene already present in their common ancestor. In contrast, genes are 'paralogous' when homologous sequences are generated by a gene duplication event. Due to this history of receptor identification and terminology, the two receptors of the $D_{1}$ family are called $D_{1}$ and $D_{5}$ in humans, but are often called $\mathrm{D}_{1 \mathrm{~A}}$ and $\mathrm{D}_{1 \mathrm{~B}}$ in nonhumans.

Interestingly, $\mathrm{D}_{1}$ and $\mathrm{D}_{2}$ dopamine receptors are not phylogenetically more related to each other than to other monoamine receptors [Callier et al., 2003; Le Crom et al., 2003; Yamamoto et al., 2013] (fig. 1b). This suggests that the ability to bind dopamine, shared by the two receptors, was acquired independently by convergence during evolution.
To summarize, five receptor genes have been isolated from mammalian species, and they were assigned either to the $D_{1}$ or to $D_{2}$ families. $D_{1}$ and $D_{5}$, also referred to as as $\mathrm{D}_{1 \mathrm{~A}}$ and $\mathrm{D}_{1 \mathrm{~B}}$ in nonhuman vertebrates, belong to the $D_{1}$ receptor family while $D_{2}, D_{3}$ and $D_{4}$ belong to the $D_{2}$ receptor family. Note that the two dopamine receptor 'families' are also called 'classes'. These terms are interchangeable and the former is often used in the field of molecular biology, referring to gene families, while the latter is often used in the field of pharmacology. Here we will use the term 'family' throughout this review.

\section{Additional $D_{1}$ Family Dopamine Receptor Genes in Nonmammalian Species}

When additional dopamine receptor subtypes were found in nonmammalian species, the classification and nomenclature of dopamine receptors became further complicated. A third subtype in the $\mathrm{D}_{1}$ family, named $\mathrm{D}_{1 \mathrm{C}}$, was initially characterized in Xenopus laevis [Sugamori et al., 1994] and then in some teleosts such as tilapia, eel and carp [Lamers et al., 1996; Cardinaud et al., 1997; Hirano et al., 1998]. Similar to the other $D_{1}$ family members, it is encoded by an intronless gene and is able to enhance adenylyl cyclase activity in transfected cells, but its sequence, pharmacological profile and resistance to desensitization make it significantly different from other $\mathrm{D}_{1}$ family receptors [Sugamori et al., 1994; Cardinaud et al., 1997; Le Crom et al., 2004]. The $\mathrm{D}_{1 \mathrm{C}}$ receptor was named following the rat nomenclature; therefore, all subsequently identified receptor genes of the $D_{1}$ family were named in the alphabetical order. The $\mathrm{D}_{1 \mathrm{D}}$ receptor, isolated from the chicken genome [Demchyshyn et al., 1995], displays different pharmacological profiles from the Xenopus and teleost $\mathrm{D}_{1 \mathrm{C}}$ receptor, with relatively low protein sequence identity, and is thus considered to be a separate subtype. A $D_{1 D}$ receptor gene was then also found in zebra finch [Kubikova et al., 2010], which suggested that the $D_{1 D}$ receptor subtype may be specific to birds. An additional $\mathrm{D}_{1}$ receptor subtype was found in the carp retina. Although its deduced protein structure is similar to that of the $D_{1}$ family, the sequence of its third cytoplasmic loop contains a unique amino acid stretch 'RTCPLQHRAI', which is not present in any other dopamine receptor of the $\mathrm{D}_{1}$ family. Without any pharmacological/physiological characterization, it was named $\mathrm{D}_{1 \mathrm{X}}$, as an 'unidentified' subtype of the $\mathrm{D}_{1}$ family [Hirano et al., 1998].

The availability of large sets of genome sequences from numerous vertebrate species enabled undertaking exten- 
Fig. 2. Four subtypes of $D_{1}$ family dopamine receptors in Osteichthyes. Here is presented a phylogenetic tree of protein sequences of $\mathrm{D}_{1}$ family dopamine receptors obtained from the maximum likelihood method using PhyML 3.0 [Guindon and Gascuel, 2003; Dereeper et al., 2008; Guindon et al., 2010]. $\mathrm{D}_{1}$-like sequences from coelacanth, gar (http://www.ensembl.org/ index.html) and elephant shark (http:// esharkgenome.imcb.a-star.edu.sg/blast/) were added to the set of protein sequences used in Yamamoto et al. [2013]. The tree was rooted on the amphioxus $\mathrm{D}_{1}$-like dopamine receptor (AmphiAmR1). Bootstrap values are indicated in red (color in online version only), and the length of the horizontal lines is proportional to sequence divergence (scale bar: 2.0 arbitrary units). All $D_{1}$ family receptors found in gnathostomes (jawed vertebrates) belong to the clade of either $\mathrm{D}_{1 \mathrm{~A}}, \mathrm{D}_{1 \mathrm{~B}}, \mathrm{D}_{1 \mathrm{C}}$ or $\mathrm{D}_{1 \mathrm{E}}$, identified in Yamamoto et al. [2013], suggesting that the four subtypes preexisted in the gnathostome ancestor (a simplified tree is shown at the top left). Teleosts have additional copies in each subtype, except in $\mathrm{D}_{1 \mathrm{E}}$. The nomenclature of the dopamine receptor subtypes follows as proposed in Yamamoto et al. [2013].

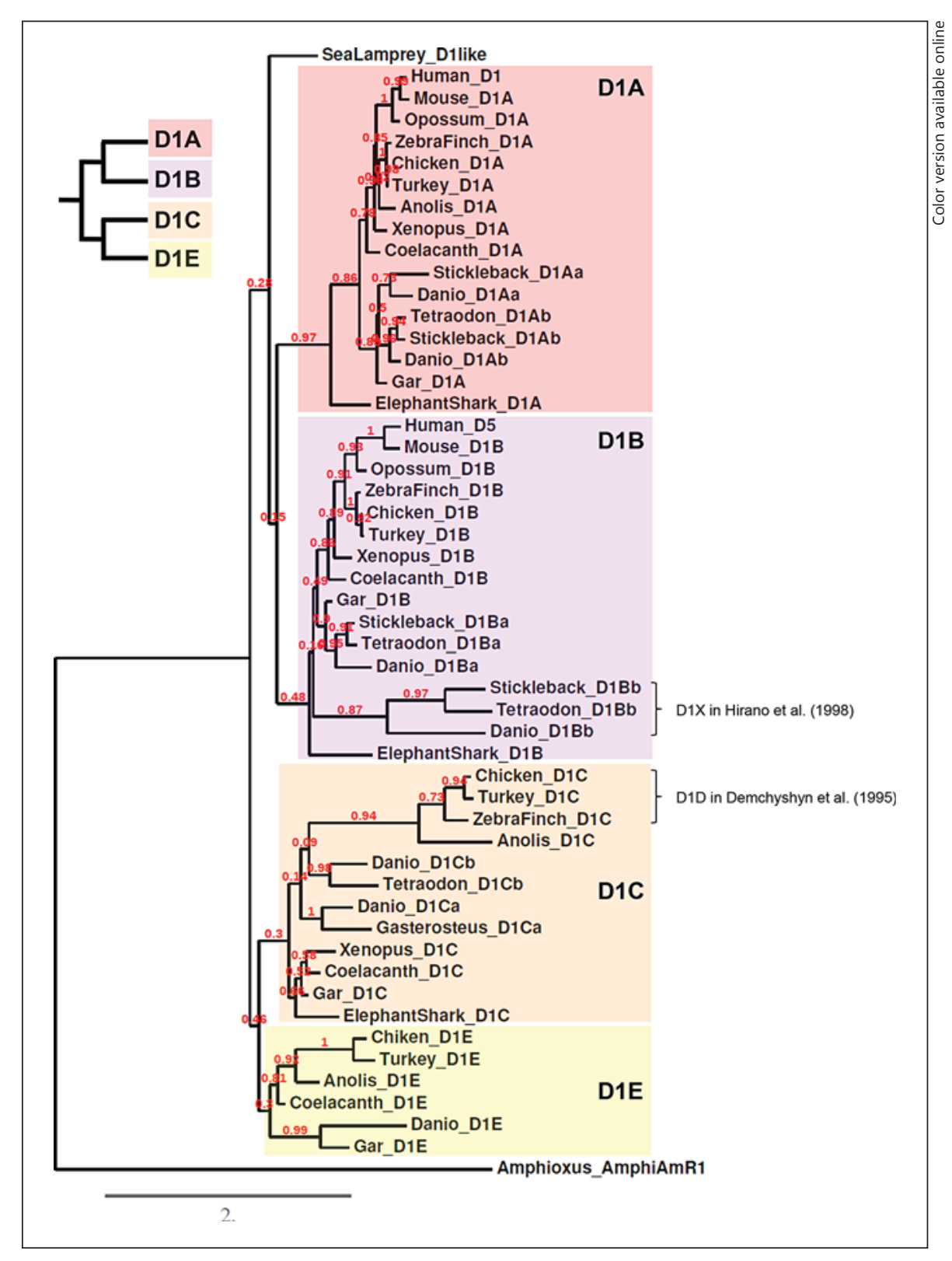

sive phylogenetic analysis of $\mathrm{D}_{1}$ family dopamine receptor sequences, spurring us to propose a renewed classification of the $\mathrm{D}_{1}$ family [Yamamoto et al., 2013] (fig. 2). Firstly, we demonstrated that anamniote $D_{1 C}$ and avian $D_{1 D}$ receptor genes are in fact orthologous, not paralogous as originally proposed. Therefore, the avian $D_{1 D}$ was renamed to $D_{1 C}$ to make the nomenclature compliant with the phylogenetic classification. We also found that the carp $D_{1 X}$ receptor sequence is one of the $D_{1 B}$ paralogous genes, probably as a result of teleost-specific genome duplication [Jaillon et al., 2004]. To account for this finding, the $D_{1 B}$ sequence was renamed to $D_{1 B a}$, and $D_{1 X}$ was renamed to $D_{1 B b}$. Finally, we found a previously unidentified $D_{1}$ receptor gene in the genomes of zebrafish and several sauropsid species, which we named the $D_{1 E}$ receptor to avoid any confusion with the previous avian $D_{1 D}$ receptor (currently reclassified as the amniote $D_{1 C}$ receptor).

Thus, based on phylogenetic analysis, it appears that ancestral Osteichthyes possessed four paralogous genes of the $\mathrm{D}_{1}$ family dopamine receptors: $D_{1 A}, D_{1 B(X)}, D_{1 C}$ (previously characterized as $D_{1 D}$ in birds) and $D_{1 E}$ receptor genes. As a consequence of gene duplications and gene losses, the repertoire of the $D_{1}$ family receptor genes 
differs between vertebrate lineages. For instance, the $D_{1 C}$ receptor gene has been secondarily lost in the mammalian lineage, and the $D_{1 E}$ receptor gene has been lost independently in several lineages of modern vertebrates. As a consequence, mammals have kept only two of the ancestral subtypes, while some species such as chicken, turkey, coelacanth, and zebrafish have kept all four subtypes. In addition, zebrafish possess seven $\mathrm{D}_{1}$ family receptor genes resulting from four ancestral subtypes, i.e. they have two paralogous genes for each subtype of the $D_{1}$ family except for the $D_{1 E}$ receptor.

The recent genome sequencing of elephant shark (Callorhinchus milii), a Chondrichthyes (cartilaginous fish) [Venkatesh et al., 2014], allowed us to further specify the evolution of $\mathrm{D}_{1}$ family receptor genes in jawed vertebrates. Three $D_{1}$-like sequences were found in the elephant shark genome, and they belong to the $\mathrm{D}_{1 \mathrm{~A}}, \mathrm{D}_{1 \mathrm{~B}}$ and $\mathrm{D}_{1 \mathrm{C}}$ subtypes (fig. 2 ). This suggests that the four $\mathrm{D}_{1}$ family receptor subtypes found in Osteichthyes probably existed before the split of Osteichthyes from Chondrichthyes, and thus were present in the gnathostome ancestor.

The pharmacological characterization of $D_{1}$ family dopamine receptors does not necessarily fit with the phylogenetic relationships. As described above, the avian $\mathrm{D}_{1 \mathrm{C}}$ was misidentified as ' $\mathrm{D}_{1 \mathrm{D}}$ ' due to its pharmacological and physiological properties which are significantly different from ' $\mathrm{D}_{1 \mathrm{C}}$ ' in amphibians and teleosts [Demchyshyn et al., 1995]. Similarly, the amphioxus 'AmphiD1/ $\beta$ ' receptor has pharmacological properties similar to the vertebrate $D_{1}$ family, but it is phylogenetically closer to the vertebrate $\beta$-adrenergic receptors [Candiani et al., 2005; Burman et al., 2007, 2009]. A more recently identified 'AmphiAmR1' is the amphioxus gene phylogenetically closest to the vertebrate $D_{1}$, and is prob-

Fig. 3. Five subtypes of $\mathrm{D}_{2}$ family dopamine receptors in Osteichthyes. Here is presented a phylogenetic tree of protein sequences of $\mathrm{D}_{2}$ family dopamine receptors obtained from the maximum likelihood method using PhyML 3.0 [Guindon and Gascuel, 2003; Dereeper et al., 2008; Guindon et al., 2010]. The protein sequences from various vertebrate species were obtained from the Ensembl genome browser (http://www.ensembl.org/index.html), GenBank (http://www.ncbi.nlm.nih.gov/genbank/) and Elephant Shark Genome Project (http://esharkgenome.imcb.a-star.edu.sg/), and they were aligned using ClustalW2 (http://www.ebi.ac.uk/Tools/msa/ clustalw2/). The tree was rooted on Drosophila $\mathrm{D}_{2}$-like dopamine receptor (DopR2). Bootstrap values are indicated in red (color in online version only), and the length of the horizontal lines is proportional to sequence divergence (scale bar: 2.0 arbitrary units). In addition to the conventionary $\mathrm{D}_{2}, \mathrm{D}_{3}$ and $\mathrm{D}_{4}$, additional clades of $\mathrm{D}_{2 \mathrm{l}}$ and $\mathrm{D}_{4 \text {-rs }}$ are formed (a simplified tree is shown at the top left). ably a $\mathrm{D}_{1}$ ortholog [Burman et al., 2007; Yamamoto et al., 2013]. Altogether, these analyses suggest that functional properties of monoamine receptors are quite plastic during evolution.

\section{Additional $D_{2}$ Family Dopamine Receptor Genes in Nonmammalian Species}

Relationships of the different $\mathrm{D}_{2}$ family receptor sequences found in nonmammalian species are not clear, and there is no recent classification that takes into account a wide range of vertebrate species.

It has been shown that zebrafish possess three $D_{2}$-like receptor genes and three $D_{4}$-like receptor genes. Initially, they were named $D_{2 a}, D_{2 b}$ and $D_{2 c}$ [Boehmler et al., 2004] and $D_{4 a}, D_{4 b}$ and $D_{4 o}$ respectively [Boehmler et al., 2007]. Later, the nomenclature of the three $D_{2}$ and $D_{4}$ receptor genes was changed in zebrafish databases such as Ensembl (http://www.ensembl.org/Danio_rerio/Info/ Index) and ZFIN (http://zfin.org/). The $D_{2 b}$ sequence was renamed as $D_{2 l i k e}\left(D_{2 l}\right)$ to account for the significant difference of this receptor sequence from the other two paralogous genes, and the $D_{2 c}$ sequence was renamed as $D_{2 b}$. Similarly, the $D_{4 b}$ sequence was renamed as $D_{4-\text { related sequence }}\left(D_{4-r s}\right)$, and the former $D_{4 c}$ was renamed as $D_{4 b}$.

In order to clarify the classification of the dopamine receptors of the $\mathrm{D}_{2}$ family in vertebrates, we carried out a phylogenetic analysis using the maximum likelihood method [Dereeper et al., 2008] on the protein sequences of this family from a wide range of vertebrate groups. In addition to the well-defined subtypes of the $D_{2}, D_{3}$ and $D_{4}$ receptors, two additional clades were identified: one con-

The right panel shows comparative gene syntenies of the chromosome loci bearing $D_{2}, D_{2 l}, D_{3}, D_{4}$ and $D_{4-r s}$ receptor genes in representative vertebrate species. Gene synteny also supports the nonorthologous relationship between $D_{2}$ and $D_{2 l}$, as well as between $D_{4}$ and $D_{4-r s}$. Orthologs of the neighbor genes of $D_{2 l}$ (ETHE1 and XRCC1) are found on the human chromosome 19, but the $D_{2 l}$ locus is replaced by another gene (ZNF575). The presence of $D_{2}$ and $D_{2 l}$ genes in genomes of coelacanth and gar, in addition to those of teleosts, strongly suggests that they preexisted before the Sarcopterygii-Actinopterygii split, instead of being duplicated as a consequence of the teleost-specific genome duplication. The absence of $D_{2 l}$ and $D_{4-r s}$ in tetrapods suggests that they were secondarily lost before the divergence of tetrapods. The nomenclature of the dopamine receptor subtypes follows rules proposed in ZFIN (http:// zfin.org/).

(For figure see next page.) 
taining the zebrafish $D_{2 l}$ receptor, and the other containing the zebrafish $D_{4-r s}$ receptor (fig. 3). Importantly, genomes of coelacanth (the order of Coelacanthformes which is a nontetrapod Sarcopterygii) and of gar (the or- der of Lepisosteiformes which is a nonteleost Actinopterygii) have sequences that are orthologous to the zebrafish $D_{2 l}$ and $D_{4-r s}$ receptors, thus strongly suggesting that the $D_{2 l}$ and $D_{4-r s}$ receptor genes are not specific to the te-

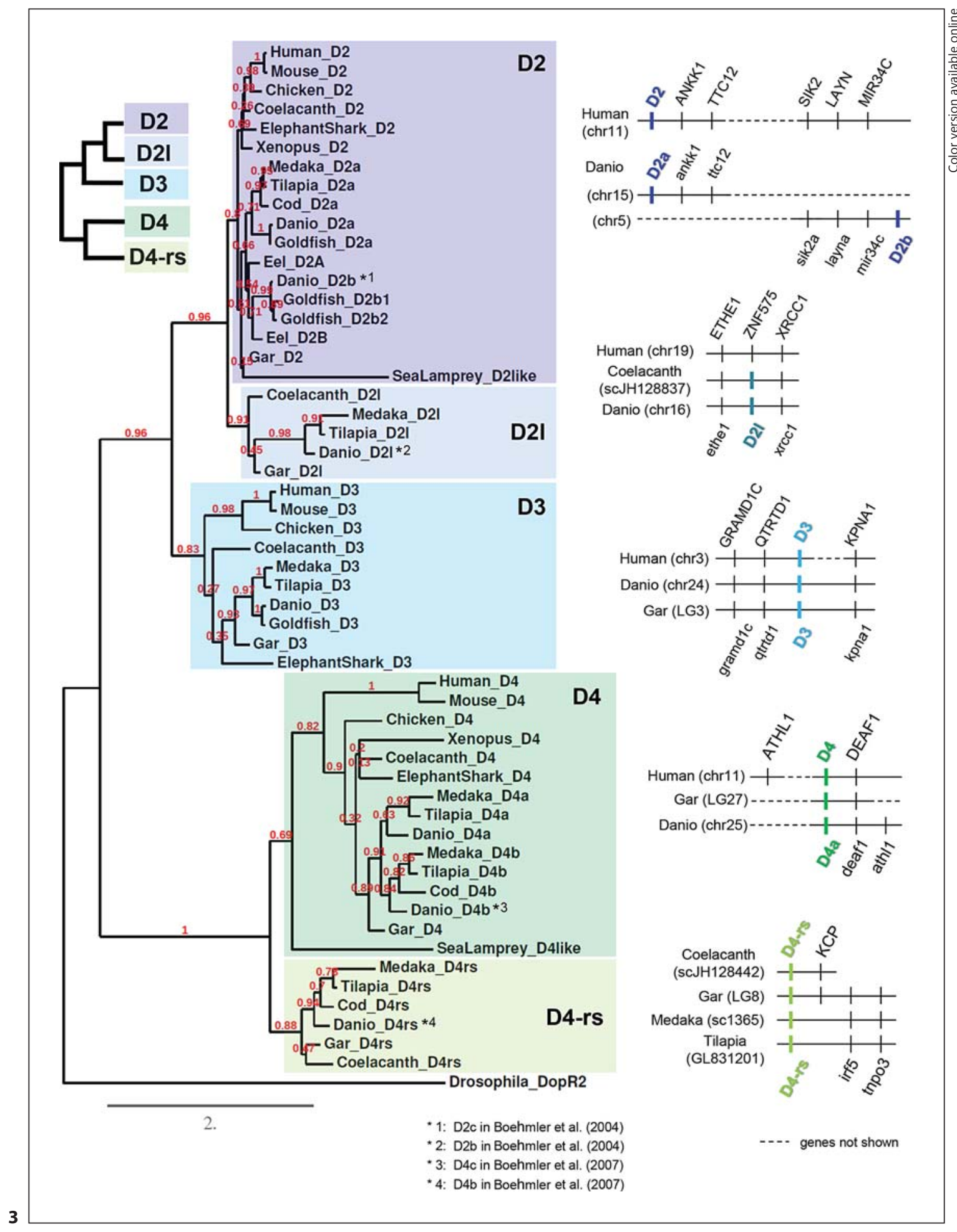




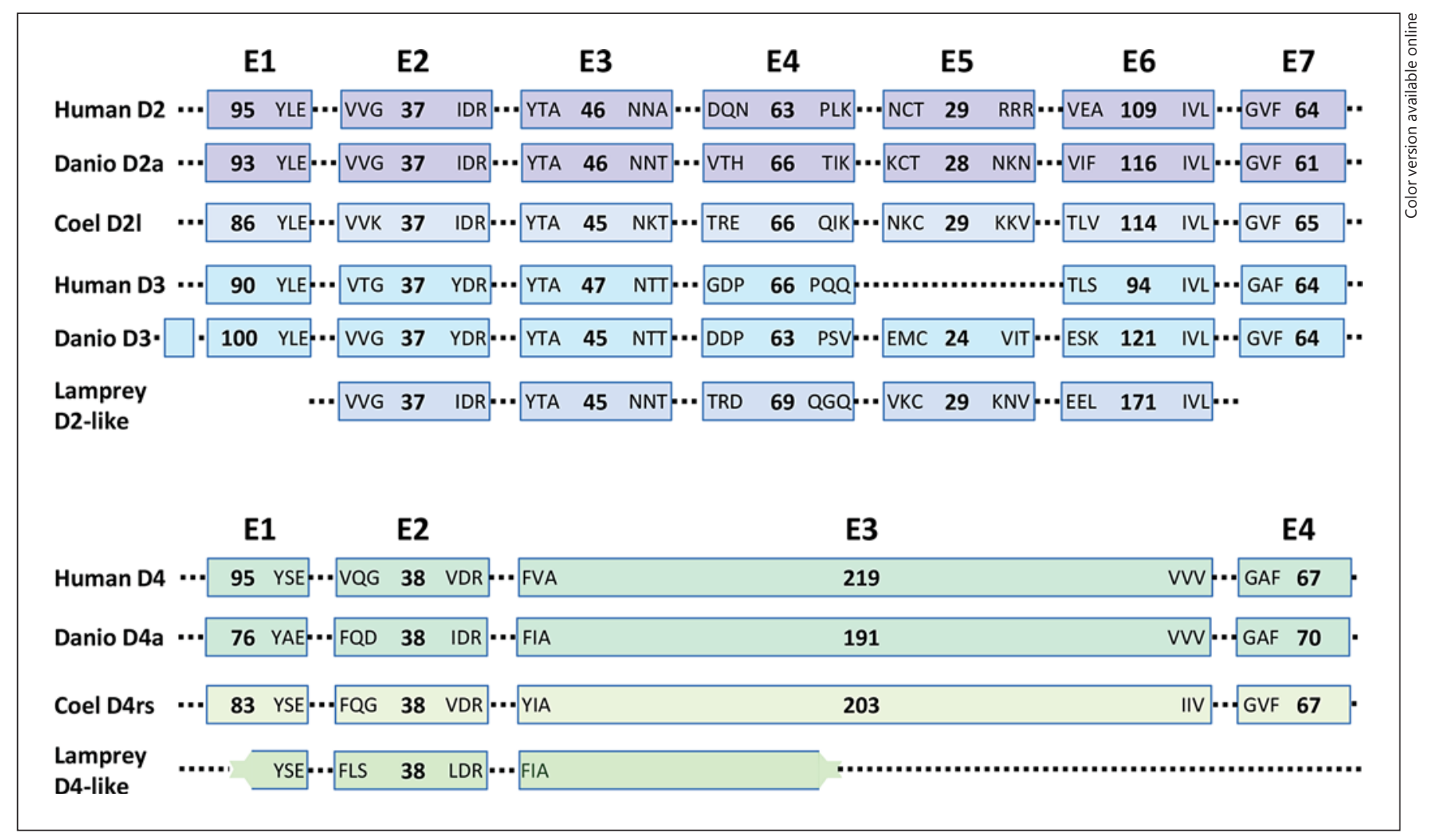

Fig. 4. Exon-intron organization of dopamine receptor genes of the $\mathrm{D}_{2}$ family. For each gene, boxes correspond to coding exons (E) and the dashed lines correspond to intron or noncoding regions of the genes. The size of the boxes and lines is arbitrary. The number of amino acids encoded by each exon is indicated within the box, except when the coding sequence is not complete. Three amino acids at the exon-intron boundary are also shown, even when the splicing site does not respect the coding phase of the sequence. For the $D_{2}, D_{3}$ and $D_{4}$ dopamine receptor subtypes, human and zebrafish (Danio) sequences are shown as representative examples of gnathostome genes. For the $D_{2 l}$ and $D_{4-r s}$ receptor subtypes, the coelacanth (Coel) has been chosen as a descendant of early diverging gnathostomes. Although incomplete, the sequences of the $\mathrm{D}_{2}$ like and $\mathrm{D}_{4}$-like receptors of lamprey are also shown, as representative of agnathans. The genomic sequences of the $D_{2} / D_{2 l} / D_{3}$ receptors encompass seven exons separated by introns branching at

leost lineage, but preexisted in the common ancestor of Osteichthyes.

Gene synteny describes the physical colocalization of two or more genes at a given locus on the same chromosome, and the presence of shared synteny between species is a good indication that the genomic region is conserved from a common ancestor. We also performed gene synteny analysis and found that, consistent with the published data [Boehmler et al., 2004], syntenic genes of the zebrafish $D_{2 a}$ (chromosome 15) and $D_{2 b}$ receptor exactly the same place for the three paralogous sequences in different species, from teleost to mammals. The amino acids at the exonintron boundary are also generally highly conserved. The $D_{4} / D_{4-r s}$ receptors are translated from four exons only, with intron sequences located again at the same place in the genomic sequences available from different species. In these subtypes, the two first exons and the last one are conserved with those of the $D_{2} / D_{2 l} / D_{3}$ receptor genes, and the third exon corresponds to a fusion of exons $3,4,5$ and 6 of the $D_{2} / D_{2 l} / D_{3}$ receptor genes. This gene organization is also found for the lamprey genes, even if their sequence is only partial. Taken together, the organization of the gene sequences of the $\mathrm{D}_{2}$ family clearly underlines the existence of two groups originating from two ancestral paralogous genes, the first one comprising the $D_{2} / D_{2 l} / D_{3}$ receptor genes and the second one comprising the $D_{4} / D_{4-r s}$ receptor genes.

genes (previously named $D_{2 c}$; chromosome 5 ) are found on the chromosomes bearing the $D_{2}$ gene in several tetrapod species (human chromosome 11, mouse chromosome 9, turkey chromosome 26). By contrast, tetrapod genomes did not show conserved synteny with the $D_{2 l}$ (previously named $D_{2 b}$ in zebrafish) locus. This supports the notion that the teleost $D_{2 l}$ receptor gene is not orthologous to the tetrapod $D_{2}$. The conserved gene synteny of the $D_{4}$ loci was less obvious. Nonetheless, we also found some conservation between the $D_{4 a}$ locus of sev- 
eral teleost species and the $D_{4}$ locus in tetrapods, coelacanth and gar. A conserved synteny of the $D_{4-r s}$ (previously named $D_{4 b}$ in zebrafish [Boehmler et al., 2007]) locus was found on the chromosomes of coelacanth and gar, but not of tetrapods.

Altogether, it is likely that the ancestors of Osteichthyes possessed five $\mathrm{D}_{2}$ family dopamine receptor genes: $D_{2}, D_{3}, D_{4}, D_{2 l}$ and $D_{4-r s}$ receptor genes. Since none of the tetrapod species possess $D_{2 l}$ or $D_{4-r s}$ receptor genes, they have probably been secondarily lost before the divergence of tetrapods.

The exon-intron organization of $\mathrm{D}_{2}$ family receptor genes displays high similarity among the $D_{2}, D_{2 l}$ and $D_{3}$ receptor genes on the one hand, and $D_{4}$ and $D_{4-r s}$ receptor genes on the other (fig. 4). The genomic sequences of $D_{2} / D_{2 l} / D_{3}$ receptors encompass seven exons. In contrast, $D_{4} / D_{4-r s}$ receptors encompass only four exons, and the third exon corresponds to a fusion of exons $3,4,5$ and 6, which are present in the $D_{2} / D_{2 l} / D_{3}$ receptor genes. Interestingly enough, the lamprey genome exhibits two genes corresponding to the $\mathrm{D}_{2}$ family: one displaying the exonintron organization similar to the $D_{2} / D_{2 l} / D_{3}$ receptor genes, and the other to the $D_{4} / D_{4-r s}$ receptor genes. Thus, the analysis of the exon-intron organization gives credence to the two clades displayed by the phylogenetic tree.

\section{Evolutionary Scenario of Dopamine Receptor Genes in Line with the $2 \mathrm{R}$ Hypothesis}

Many genes are present as single copies in genomes of amphioxus and ascidians, whereas mammals contain three or more orthologs. Such observations led to the $2 \mathrm{R}$ hypothesis which speculates that gnathostomes (jawed vertebrates) experienced two rounds of whole-genome duplication [Lundin, 1993; Holland et al., 1994; Pébusque et al., 1998; Skrabanek and Wolfe, 1998; Panopoulou and Poustka, 2005]. Although this hypothesis is still debated, it is tempting to draw a scenario of the evolution of dopamine receptor genes in this context (fig. 5).

For the $\mathrm{D}_{1}$ family dopamine receptor genes, four paralogous genes exist in Osteichthyes, in contrast to a single $\mathrm{D}_{1}$ family receptor gene (AmphiAmR1) in the amphioxus genome [Burman et al., 2007; Yamamoto et al., 2013]. This observation fits well with the $2 \mathrm{R}$ hypothesis. Based on sequence similarity and gene synteny, the first duplication of the $\mathrm{D}_{1}$-like gene of stem chordates would have given rise to a $D_{1 A} / D_{1 B}$-like gene and a $D_{1 C} / D_{1 E}$-like gene, and the second duplication would have given rise to the four $D_{1 A}, D_{1 B}, D_{1 C}$ and $D_{1 E}$ receptor genes. The presence of the $D_{1 A}, D_{1 B}$ and $D_{1 C}$ receptor genes in elephant shark indicates that the second round of duplications probably occurred before the separation of the Osteichthyes and Chondrichthyes lineages. If one of the duplications occurred before the gnathostome-cyclostome split [Kuraku et al., 2009], two paralogs of the $D_{1}$ family receptor genes would be expected to be present in cyclostomes. However, up to now only one $\mathrm{D}_{1}$ family receptor gene, which is slightly more related to the $D_{1 A} / D_{1 B}$ receptor gene, has been found in lamprey. Since the genomic information is still incomplete in cyclostomes, it is difficult to bring support to the duplication timing in the stem vertebrates.

In the case of the $\mathrm{D}_{2}$ family receptor genes, both molecular phylogeny and intron-exon organization strongly support that the $\mathrm{D}_{2}$ family of dopamine receptors is divided into two clades, one containing $D_{2} / D_{2 l} / D_{3}$ sequences and another containing $D_{4} / D_{4-r s}$ sequences. The presence of one lamprey gene of the $\mathrm{D}_{2}$ receptor family in each clade $\left(\mathrm{D}_{2}\right.$-like and $\mathrm{D}_{4}$-like receptors) suggests that the first round of duplication occurred before the gnathostome-cyclostome split.

The dopamine receptor genes of the $\mathrm{D}_{2}$ family found in elephant shark are classified within the clades of the $\mathrm{D}_{2}$, $\mathrm{D}_{3}$ and $\mathrm{D}_{4}$ receptor sequences. This suggests that the second round of genome duplications generated the $D_{2}, D_{3}$, $D_{4}$ and $D_{4-r s}$ paralogs, and that elephant shark lost the $D_{4-r s}$ receptor gene. The $D_{2 l}$ receptor gene may have been generated by a gene duplication event that occurred after the Osteichthyes-Chondrichthyes split, and has been secondarily lost in the stem tetrapods.

Since no $\mathrm{D}_{2}$ family receptor gene has been found in the genomes of nonvertebrate chordates (tunicates and amphioxus), it is difficult to infer the situation of stem chordates. Outside of chordates, genes assigned to the ' $\mathrm{D}_{2}$ dopamine receptor family' are found in the sea urchin (a nonchordate deuterostome) as well as in several species of protostomes, based on molecular phylogenies. Considering that tunicate and cephalochordate genomes have lost numerous genes, it is possible that these two groups of chordates have independently lost genes encoding $\mathrm{D}_{2}$ family receptors.

\section{The Problem of Nomenclature of the Dopamine Receptor Genes}

The nomenclature of the dopamine receptor genes is quite confusing and unsatisfactory for two main reasons: (1) it does not seriously take into account the existence of additional dopamine receptor subtypes in nonmammalian species, and (2) the nomenclature of the two families 
Fig. 5. Hypothetical evolutionary scenario of dopamine receptor genes in vertebrates. a Evolutionary scenario of gene duplications of dopamine receptor genes drawn in line with the $2 \mathrm{R}$ hypothesis. The arrows indicate hypothetical genome duplications, and the arrowhead indicates a gene duplication. A single $D_{1}$-like and $D_{2}$-like gene in the stem chordates were probably duplicated twice, before and after the gnathostomecyclostome split, raising four subtypes in stem gnathostomes. The $D_{2}$ and $D_{2 l}$ genes were further duplicated in the stem Osteichthyes, resulting in five $\mathrm{D}_{2}$ family dopamine receptor genes in Osteichthyes. b Evolutionary scenario within the group of Osteichthyes based on the presence of dopamine receptor genes in modern species. Zebrafish possess extra copies of many subtypes, presumably due to the teleostspecific genome duplication. The tetrapod lineage has secondarily lost the $D_{2 l}$ and $D_{4-r s}$ receptor genes, and mammals have further lost $D_{1 C}$ and $D_{1 E}$ receptor genes.

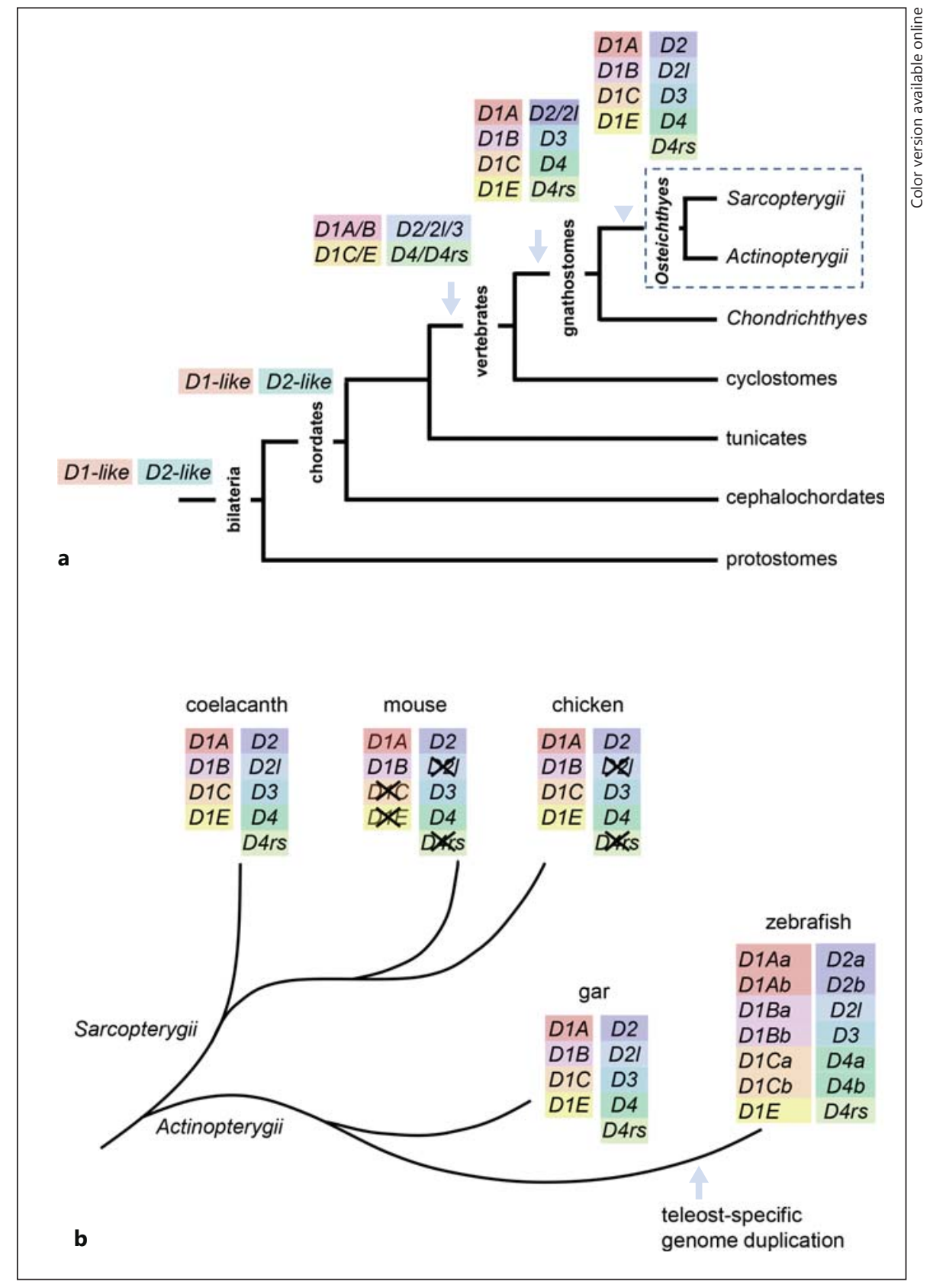

of dopamine receptors is not consistent, as alphabetical suffixes are applied for subtypes of the $D_{1}$ family $\left(D_{1 A}\right.$, $\mathrm{D}_{1 \mathrm{~B}}$ ), whereas numeric suffixes are applied for subtypes of the $\mathrm{D}_{2}$ family $\left(\mathrm{D}_{2}, \mathrm{D}_{3}, \mathrm{D}_{4}\right)$.

The IUPHAR Committee on Receptor Nomenclature and Drug Classification (http://www.guidetopharmacology.org/) considers only receptor genes which are present in the human genome. Thus, the receptor subtypes which have been lost in mammals were named independently from the IUPHAR Committee by using alphabetical suf- fixes, i.e. $D_{1 C}$ [Sugamori et al., 1994], $D_{1 D}$ [Demchyshyn et al., 1995] and $D_{1 X}$ [Hirano et al., 1998] (fig. 6a). Accordingly, the modified nomenclature proposed by Yamamoto et al. [2013], which accounts for the correct sequence relationship of the different subtypes within the $D_{1}$ family, also used the alphabetical suffix from $\mathrm{D}_{1 \mathrm{~A}}$ to $\mathrm{D}_{1 \mathrm{E}}$ (fig. 6b). As a result, the successive findings of $D_{1}$ family receptor genes in nonmammalian species resulted in a nomenclature that is inconsistent between the $\mathrm{D}_{1}$ family (alphabetical suffix) and the $\mathrm{D}_{2}$ family (numeric suffix). 


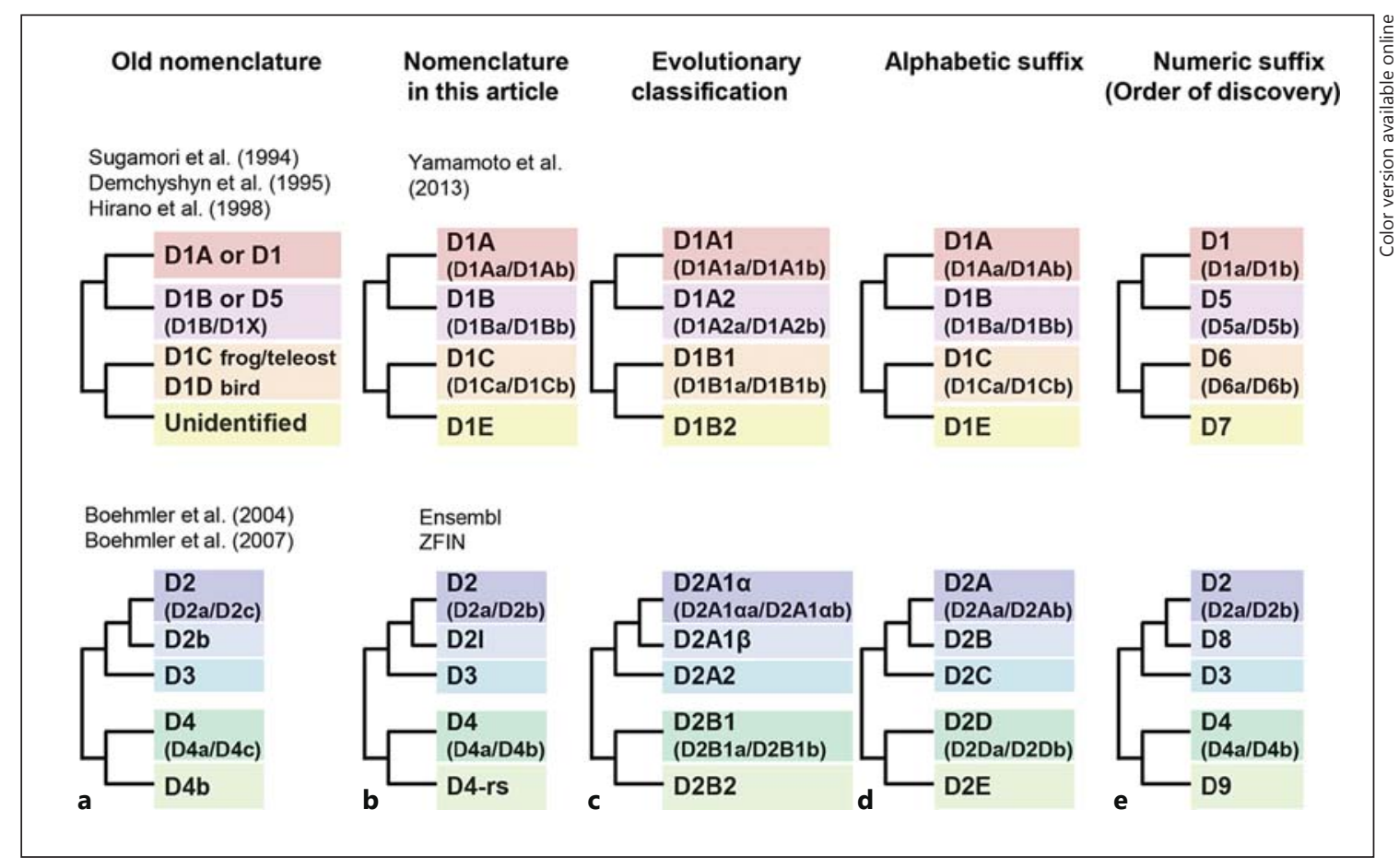

Fig. 6. Inconsistent nomenclature of dopamine receptor genes. The nomenclature of dopamine receptor genes is quite confusing because of successive findings of new subtypes in nonmammalian species and the misidentification of homologous relationships. Here we clarified the evolutionary relationships of dopamine receptor genes of both the $D_{1}$ and $D_{2}$ families, which is shown as simplified phylogenetic trees. The same phylogenetic position represents the same gene. Nomenclatures for teleost-specific paralogs are indicated in parentheses. a Old nomenclatures used in previous publications. b Nomenclatures applied in this article. Our publication on $\mathrm{D}_{1}$ family receptor genes [Yamamoto et al., 2013] fol-

Ideally, a nomenclature of receptors should be coherent with the phylogenetic classification. When we take into account the evolution of the two different classes of dopamine receptor genes in Bilateria, each receptor subtype could be classified according to duplication events. For example, the first duplication in the $D_{1}$ family would give rise to $D_{1 A}$ and $D_{1 B}$, and the second duplication would give rise to $D_{1 A 1}, D_{1 A 2}, D_{1 B 1}, D_{1 B 2}$, etc. (fig. 6c). The problem of this system is that a nomenclature cannot be fixed without performing a rigorous phylogenetic analysis. In addition, it encounters the necessity of renaming when the evolutionary classification is modified.

An alternative possibility is to distinguish the two families as $\mathrm{D}_{1}$ and $\mathrm{D}_{2}$, and arbitrarily assign an alphabetical suffix for subtypes within each family (fig. 6d). This is the case for the nonmammalian $\mathrm{D}_{1}$ family subtypes, and it follows the rule used for many other monoamine recep- lowed the alphabetical nomenclature used in earlier studies. The newly identified gene was named as $D_{1 E}$ because the ' $D_{1 D}$ ' was already used for the avian $D_{1 C}$ [Demchyshyn et al., 1995]. The nomenclature for the $\mathrm{D}_{2}$ family receptor genes followed that of Ensembl and ZFIN. c A proposition of nomenclature which is coherent with the evolutionary scenario of dopamine receptor genes. $\mathbf{d}$ A proposition of nomenclature in which subtypes within each $D_{1}$ and $D_{2}$ family are represented by letters $\left(D_{1 A}, D_{1 B}, D_{1 C}\right.$, etc. $/ D_{2 A}, D_{2 B}, D_{2 C}$, etc.). e $A$ proposition of nomenclature which reflects only chronologic order of gene discovery, and requires minimal changes from the currently accepted nomenclature. tors, such as serotonin receptor subtypes $\left(5 \mathrm{HT}_{1 \mathrm{~A}}, 5 \mathrm{HT}_{1 \mathrm{~B}}\right.$, $5 \mathrm{HT}_{1 \mathrm{C}}$, and $5 \mathrm{HT}_{2 \mathrm{~A}}, 5 \mathrm{HT}_{2 \mathrm{~B}}, 5 \mathrm{HT}_{2 \mathrm{C}}$, etc.). In this system, the alphabetic order would not necessarily reflect the evolutionary relationship, but it would keep the distinction between the $D_{1}$ and $D_{2}$ families, which are distantly related to each other. This nomenclature change would require the renaming of $\mathrm{D}_{2}$ to $\mathrm{D}_{2 \mathrm{~A}}, \mathrm{D}_{3}$ to $\mathrm{D}_{2 \mathrm{C}}$ and $\mathrm{D}_{4}$ to $\mathrm{D}_{4} \mathrm{D}$. The acceptance of such changes would not be easy since the numeric nomenclature ' $D_{2}, D_{3}$ and $D_{4}$ ' for the $D_{2}$ family is so extensively utilized.

A third possibility is to rename all the subtypes in numeric order following the current nomenclature proposed by IUPHAR. The official database of the IUPHAR and gene databases use numeric suffixes such as $D_{1}$ and $\mathrm{D}_{5}$, and the terms $\mathrm{D}_{1 \mathrm{~A}}$ and $\mathrm{D}_{1 \mathrm{~B}}$ are considered as 'previous or unofficial names'. Looking at the use of terminology in other genome databases, the current tendency of using 
numeric suffixes seems to become a rule. In the Ensembl and ZFIN databases, the zebrafish $D_{1 C}$ receptor gene has been recently renamed $D_{6}$, and the $D_{1 E}$ receptor has been renamed $D_{7}$. In this line, the additional $D_{2}$ family receptor subtypes, ' $D_{2 l}$ ' and ' $D_{4-r s}$ ', should be renamed $D_{8}$ and $D_{9}$, respectively (fig. 6e).

The problem of this last option is that it does not differentiate between the two different dopamine receptor families. However, its main advantage is that it requires a minimal change of already accepted nomenclature. To facilitate everyone using the same terminology which reflects correct orthologous relationships, naming all the dopamine receptor genes using consecutive numbering may be a good compromise. In order to achieve a nomenclature change that permits distinguishing between two different receptor families (alphabetic suffix; fig. 6d), a nomenclature consortium needs to be organized to promote an official change of the well-accepted terminology such as ' $\mathrm{D}_{2}$ ', ' $\mathrm{D}_{3}$ ' and ' $\mathrm{D}_{4}$ '.

\section{Conclusion}

The dopamine receptors have been highly diversified as a consequence of gene duplications during vertebrate evolution. Overall, nine dopamine receptor genes exist in the group of Osteichthyes: four in the $\mathrm{D}_{1}$ family $\left(D_{1}, D_{5}\right.$, $D_{6}$ and $\left.D_{7}\right)$ and five in the $\mathrm{D}_{2}$ family $\left(D_{2}, D_{3}, D_{4}, D_{8}\right.$ and $D_{9}$ ). Mammals have lost many dopamine receptor genes as compared to other vertebrate groups, keeping only five of the ancestral dopamine receptor genes (from $D_{1}$ to $D_{5}$ ).

Examining the functional significance of such receptor multiplicity is essential to gain a better understanding of the nature of dopamine neurotransmission in vertebrates. Since the duplicated paralogous genes are kept in many species, it is unlikely that all these genes are functionally redundant. Cautious evolutionary and comparative approaches will contribute to deciphering the physiological significance of the vast diversity of dopamine systems, and will enable proper interpretations of information obtained from animal models of human pathologies involving dysfunction of dopamine systems.

\section{Acknowledgements}

We thank Dr. Sylvie Dufour for important comments on an early stage of the manuscript. We also thank Drs. Anna Xavier, Michaël Demarque, Franck Bourrat and Shauna Katz for critical readings of the text. This work is supported by the CNRS and Paris-Sud University, grants from FRM, ENP, European Community (ZF-Health) and IDEX Paris-Saclay.

\section{References}

Beaulieu JM, Gainetdinov RR (2011): The physiology, signaling, and pharmacology of dopamine receptors. Pharmacol Rev 63:182-217.

Boehmler W, Carr T, Thisse C, Thisse B, Canfield VA, Levenson R (2007): $\mathrm{D}_{4}$ dopamine receptor genes of zebrafish and effects of the antipsychotic clozapine on larval swimming behaviour. Genes Brain Behav 6:155-166.

- Boehmler W, Obrecht-Pflumio S, Canfield V, Thisse C, Thisse B, Levenson R (2004): Evolution and expression of $D_{2}$ and $D_{3}$ dopamine receptor genes in zebrafish. Dev Dyn 230: 481-493.

- Bunzow JR, Van Tol HH, Grandy DK, Albert P, Salon J, Christie M, Machida CA, Neve KA, Civelli O (1988): Cloning and expression of a rat $\mathrm{D}_{2}$ dopamine receptor cDNA. Nature 336: 783-787.

-Burman C, Maqueira B, Coadwell J, Evans PD (2007): Eleven new putative aminergic G-protein coupled receptors from Amphioxus (Branchiostoma floridae): identification, sequence analysis and phylogenetic relationship. Invert Neurosci 7:87-98.
Burman C, Reale V, Srivastava DP, Evans PD (2009): Identification and characterization of a novel amphioxus dopamine $\mathrm{D}$-like receptor. J Neurochem 111:26-36.

Callier S, Snapyan M, Le Crom S, Prou D, Vincent JD, Vernier P (2003): Evolution and cell biology of dopamine receptors in vertebrates. Biol Cell 95:489-502.

-Candiani S, Oliveri D, Parodi M, Castagnola P, Pestarino M (2005): $\mathrm{AmphiD}_{1} /$ beta, a dopamine $D_{1} /$ beta-adrenergic receptor from the amphioxus Branchiostoma floridae: evolutionary aspects of the catecholaminergic system during development. Dev Genes Evol 215:631-638.

Cardinaud B, Sugamori KS, Coudouel S, Vincent JD, Niznik HB, Vernier P (1997): Early emergence of three dopamine $D_{1}$ receptor subtypes in vertebrates. Molecular phylogenetic, pharmacological, and functional criteria defining $D_{1 \mathrm{~A}}, \mathrm{D}_{1 \mathrm{~B}}$, and $\mathrm{D}_{1 \mathrm{C}}$ receptors in European eel Anguilla anguilla. J Biol Chem 272:2778-2787.

Dearry A, Gingrich JA, Falardeau P, Fremeau RT Jr, Bates MD, Caron MG (1990): Molecular cloning and expression of the gene for a human $\mathrm{D}_{1}$ dopamine receptor. Nature 347:72-76.
Demchyshyn LL, Sugamori KS, Lee FJ, Hamadanizadeh SA, Niznik HB (1995): The dopamine $\mathrm{D}_{1 \mathrm{D}}$ receptor. Cloning and characterization of three pharmacologically distinct $\mathrm{D}_{1^{-}}$ like receptors from Gallus domesticus. J Biol Chem 270:4005-4012.

-Dereeper A, Guignon V, Blanc G, Audic S, Buffet $S$, Chevenet F, Dufayard JF, Guindon S, Lefort V, Lescot M, Claverie JM, Gascuel O (2008): Phylogeny.fr: robust phylogenetic analysis for the non-specialist. Nucleic Acids Res 36:W465-W469.

Gerfen CR, Herkenham M, Thibault J (1987): The neostriatal mosaic: II. Patch- and matrix-directed mesostriatal dopaminergic and nondopaminergic systems. J Neurosci 7:39153934.

Goldman-Rakic PS (1999): The 'psychic' neuron of the cerebral cortex. Ann NY Acad Sci 868: 13-26.

- Guindon S, Dufayard JF, Lefort V, Anisimova M, Hordijk W, Gascuel O (2010): New algorithms and methods to estimate maximumlikelihood phylogenies: assessing the performance of PhyML 3.0. Syst Biol 59:307-321. 
Guindon S, Gascuel O (2003): A simple, fast, and accurate algorithm to estimate large phylogenies by maximum likelihood. Syst Biol 52: 696-704.

Hirano J, Archer SN, Djamgoz MB (1998): Dopamine receptor subtypes expressed in vertebrate (carp and eel) retinae: cloning, sequencing and comparison of five $\mathrm{D}_{1}$-like and three $\mathrm{D}_{2}$-like receptors. Receptors Channels 5:387404.

-Holland PW, Garcia-Fernandez J, Williams NA, Sidow A (1994): Gene duplications and the origins of vertebrate development. Dev Suppl, pp 125-133.

Hornykiewicz O (1966): Dopamine (3-hydroxytyramine) and brain function. Pharmacol Rev 18:925-964.

- Jaber M, Robinson SW, Missale C, Caron MG (1996): Dopamine receptors and brain function. Neuropharmacology 35:1503-1519.

Jaillon O, Aury JM, Brunet F, Petit JL, StangeThomann N, Mauceli E, Bouneau L, Fischer C, Ozouf-Costaz C, Bernot A, Nicaud S, Jaffe D, Fisher S, Lutfalla G, Dossat C, Segurens B, Dasilva C, Salanoubat M, Levy M, Boudet N, Castellano S, Anthouard V, Jubin C, Castelli V, Katinka M, Vacherie B, Biemont C, Skalli Z, Cattolico L, Poulain J, De Berardinis V, Cruaud C, Duprat S, Brottier P, Coutanceau JP, Gouzy J, Parra G, Lardier G, Chapple C, McKernan KJ, McEwan P, Bosak S, Kellis M, Volff JN, Guigo R, Zody MC, Mesirov J, Lindblad-Toh K, Birren B, Nusbaum C, Kahn D, Robinson-Rechavi M, Laudet V, Schachter V, Quetier F, Saurin W, Scarpelli C, Wincker P, Lander ES, Weissenbach J, Roest Crollius $\mathrm{H}$ (2004): Genome duplication in the teleost fish Tetraodon nigroviridis reveals the early vertebrate proto-karyotype. Nature 431:946-957.

-Jarvie KR, Tiberi M, Silvia C, Gingrich JA, Caron MG (1993): Molecular cloning, stable expression and desensitization of the human dopamine $\mathrm{D}_{1 \mathrm{~b}} / \mathrm{D}_{5}$ receptor. J Recept Res 13:573590.

Kebabian JW, Calne DB (1979): Multiple receptors for dopamine. Nature 277:93-96.

-Kehagia AA, Murray GK, Robbins TW (2010): Learning and cognitive flexibility: frontostriatal function and monoaminergic modulation. Curr Opin Neurobiol 20:199-204.

Kubikova L, Wada K, Jarvis ED (2010): Dopamine receptors in a songbird brain. J Comp Neurol 518:741-769.
Kuraku S, Meyer A, Kuratani S (2009): Timing of genome duplications relative to the origin of the vertebrates: did cyclostomes diverge before or after? Mol Biol Evol 26:47-59.

Lamers AE, Groneveld D, de Kleijn DP, Geeraedts FC, Leunissen JA, Flik G, Wendelaar Bonga SE, Martens GJ (1996): Cloning and sequence analysis of a hypothalamic cDNA encoding a $\mathrm{D}_{1 \mathrm{c}}$ dopamine receptor in tilapia. Biochim Biophys Acta 1308:17-22.

Le Crom S, Kapsimali M, Barome PO, Vernier P (2003): Dopamine receptors for every species: gene duplications and functional diversification in Craniates. J Struct Funct Genomics 3: 161-176.

Le Crom S, Sugamori KS, Sidhu A, Niznik HB, Vernier P (2004): Delineation of the conserved functional properties of $\mathrm{D}_{1 \mathrm{~A}}, \mathrm{D}_{1 \mathrm{~B}}$ and $\mathrm{D}_{1 \mathrm{C}}$ dopamine receptor subtypes in vertebrates. Biol Cell 96:383-394.

Lundin LG (1993): Evolution of the vertebrate genome as reflected in paralogous chromosomal regions in man and the house mouse. Genomics 16:1-19.

- Matsumoto N, Hanakawa T, Maki S, Graybiel AM, Kimura M (1999): Role of nigrostriatal dopamine system in learning to perform sequential motor tasks in a predictive manner. J Neurophysiol 82:978-998.

Missale C, Nash SR, Robinson SW, Jaber M, Caron MG (1998): Dopamine receptors: from structure to function. Physiol Rev 78:189225 .

Monsma FJ Jr, Mahan LC, McVittie LD, Gerfen CR, Sibley DR (1990): Molecular cloning and expression of a $\mathrm{D}_{1}$ dopamine receptor linked to adenylyl cyclase activation. Proc Natl Acad Sci USA 87:6723-6727.

Panopoulou G, Poustka AJ (2005): Timing and mechanism of ancient vertebrate genome duplications - the adventure of a hypothesis. Trends Genet 21:559-567.

- Pébusque MJ, Coulier F, Birnbaum D, Pontarotti P (1998): Ancient large-scale genome duplications: phylogenetic and linkage analyses shed light on chordate genome evolution. Mol Biol Evol 15:1145-1159.

Schultz W (1998): Predictive reward signal of dopamine neurons. J Neurophysiol 80:1-27.

- Sidhu A, Niznik HB (2000): Coupling of dopamine receptor subtypes to multiple and diverse G proteins. Int J Dev Neurosci 18:669677.

-Skrabanek L, Wolfe KH (1998): Eukaryote genome duplication - where's the evidence? Curr Opin Genet Dev 8:694-700.
Sokoloff P, Giros B, Martres MP, Bouthenet ML, Schwartz JC (1990): Molecular cloning and characterization of a novel dopamine receptor $\left(D_{3}\right)$ as a target for neuroleptics. Nature 347:146-151.

Sugamori KS, Demchyshyn LL, Chung M, Niznik $\mathrm{HB}$ (1994): $\mathrm{D}_{1 \mathrm{~A}}, \mathrm{D}_{1 \mathrm{~B}}$, and $\mathrm{D}_{1 \mathrm{C}}$ dopamine receptors from Xenopus laevis. Proc Natl Acad Sci USA 91:10536-10540.

- Sunahara RK, Guan HC, O'Dowd BF, Seeman P, Laurier LG, Ng G, George SR, Torchia J, Van Tol HH, Niznik HB (1991): Cloning of the gene for a human dopamine $\mathrm{D}_{5}$ receptor with higher affinity for dopamine than $\mathrm{D}_{1}$. Nature 350:614-619.

Tiberi M, Jarvie KR, Silvia C, Falardeau P, Gingrich JA, Godinot N, Bertrand L, Yang-Feng TL, Fremeau RT Jr, Caron MG (1991): Cloning, molecular characterization, and chromosomal assignment of a gene encoding a second $\mathrm{D}_{1}$ dopamine receptor subtype: differential expression pattern in rat brain compared with the $\mathrm{D}_{1 \mathrm{~A}}$ receptor. Proc Natl Acad Sci USA 88: 7491-7495.

Tuomisto J, Mannisto P (1985): Neurotransmitter regulation of anterior pituitary hormones. Pharmacol Rev 37:249-332.

Vallone D, Picetti R, Borrelli E (2000): Structure and function of dopamine receptors. Neurosci Biobehav Rev 24:125-132.

Van Tol HH, Bunzow JR, Guan HC, Sunahara RK, Seeman P, Niznik HB, Civelli O (1991): Cloning of the gene for a human dopamine $\mathrm{D}_{4}$ receptor with high affinity for the antipsychotic clozapine. Nature 350:610-614.

-Venkatesh B, Lee AP, Ravi V, Maurya AK, Lian MM, Swann JB, Ohta Y, Flajnik MF, Sutoh Y, Kasahara M, Hoon S, Gangu V, Roy SW, Irimia M, Korzh V, Kondrychyn I, Lim ZW, Tay BH, Tohari S, Kong KW, Ho S, LorenteGaldos B, Quilez J, Marques-Bonet T, Raney BJ, Ingham PW, Tay A, Hillier LW, Minx P, Boehm T, Wilson RK, Brenner S, Warren WC (2014): Elephant shark genome provides unique insights into gnathostome evolution. Nature 505:174-179.

Vogt M (1973): Functional aspects of the role of catecholamines in the central nervous system. Br Med Bull 29:168-172.

-Yamamoto K, Mirabeau O, Bureau C, Blin M, Michon-Coudouel S, Demarque M, Vernier P (2013): Evolution of dopamine receptor genes of the $\mathrm{D}_{1}$ class in vertebrates. Mol Biol Evol 30: 833-843. 